\title{
Leadership among women working to eradicate female genital mutilation: the impact of transcultural moments
}

Jose Siles-González ( $\square$ jose.siles@ua.es )

Escuela Oficial de Idiomas de Alicante Departamento de Ingles https://orcid.org/0000-0003-3046-639X Ana Isabel Gutiérrez-García

Universitat d'Alacant

Carmen Solano-Ruíz

Universitat d'Alacant

\section{Research}

Keywords: Female genital mutilation, transcultural nursing, women health, cultural moments, critical thinking

Posted Date: April 15th, 2020

DOl: https://doi.org/10.21203/rs.3.rs-21941/v1

License: (c) (i) This work is licensed under a Creative Commons Attribution 4.0 International License. Read Full License 


\section{Abstract}

\section{Background}

The study aims to describe the transcultural process through which immigrant women who have experienced female genital mutilation become leaders against this practice. This study also aims to identify the incidence of female genital mutilation in the invisibility of health problems (especially sexual and reproductive disorders).

\section{Method}

Descriptive research with cross-cultural principles and a qualitative approach. A semi-structured interview was used for data collection. Inclusion criteria: the women investigated had undergone female genital mutilation and were fully prepared to discuss the issue.

\section{Results}

Staying and social relations in a different country reduce cultural pressure and promotes critical thinking. Cultural moments reflect the different situations that affect the thinking and practice of female genital mutilation. Health problems associated with female genital mutilation (sexual, reproductive and psychological) become visible at transcultural moments.

\section{Conclusions}

The country change affects the cultural pressure that keeps this practice in minds, institutions, structures and bodies. These changes produce the transcultural moments. The practice of female genital mutilation constitutes a significant segment of gender-based violence.

\section{Plain English Summary}

This study reveals the perceptions of immigrant women living in Spain about the practice of Female Genital Mutilation (FGM) and the transcultural change which transforms these women into leaders against the practice. This research links this transcultural change with the visibility of the health problems derived from FGM. This study was part of the 'Social Challenges Europe 2020 strategy program, which considers current political priorities in the field of European strategy, especially focusing on health, demographic change, well-being, and the integration of gender analysis.

Preliminary Observation and Analysis Unit comprised 18 women (W1-18) who had experienced FGM. The secondary observation and analysis unit comprised seven women Leaders (WL1-7) who had all lived through transcultural moments and had become activists in the advocate against FGM. We used semi-structured interviews with the dialectical structural model of care (DSMC) as the data analysis method. 
When these women contact with other cultures, they can access different values, beliefs, and norms. Identification of health problems derived from the GFM: urinary tract infections, sexual pain, pregnancy, delivery and psychological problems (women understood that these problems were not the usual ones when they interacted with women from other cultures (transcultural moments).

Conclusions: This study reveals evidence that links transcultural moments with the process of changing women's attitudes towards their role against the GFM. This change process is in line with the visibility of the health problems derived from the GFM.

\section{Background}

The aim of this study was to describe the process of gaining awareness and acculturation through which women who have experienced female genital mutilation (FGM) become leaders that advocate against this practice. Our specific objectives were (a) to understand the experiences lived by women who have experienced FGM and who now work towards its eradication; (b) Describe the impact of gender on the normalization and invisibility of health problems arising from FGM; (c) identify cultural moments lived by women who have experienced FGM; (d) describe the factors that facilitate or hinder awareness of FGM from the perspective of the dialectical structural model of care; e) Describe the impact of "habitus", "logical conformism" and "Technologies of the self" in the process of socializing FGM. This study was part of the 'Social Challenges Europe 2020 strategy' program, which considers current political priorities in the field of European strategy, especially focusing on health, demographic change, well-being, and the integration of gender analysis-all of which is inherent within the subject of FGM.

At the international level, Grassivaro Gallo \& Busatta studied the perceptions of the practice of FGM in Uganda'[1]. Kerubo focused your study on the experiences of women by examining their memories before and after the mutilation[2]. Also, Ali made references to other stated reasons for FGM such as social pressure, the maintenance of female virginity, hygiene, and economic explanations[3]. Several articles, such as that by Abathun, Sundby and Gele (2012), Berg and Denison (2012), and Isman, Ekéus \& Berggrena (2013) describe the attitudes and changing behaviour towards the adoption of a position against this practice $[4,5,6]$, which often becomes evident among immigrants who started to reside in European countries after the FGM and after a process of acculturation. In Europe, women who are at risk or who have already experienced FGM can use this practice as a basis for the so-called cause of asylum. Other studies have focused on analyzing the psychological effects of FGM, which can include posttraumatic stress disorders and memory problems, among others (Behrendt \& Moritz, 2005)[7]. An article describes three cultural moments in which women's level of acculturation or social and communicative integration identified by analyzing the impact of multicultural, intercultural, and transcultural factors in the maintenance, questioning, or abandonment of the ideology of FGM[8]. In Spain, work has been done as part of the theses of Pastor (2014) and Jiménez Ruiz (2015) to give women who have experienced FGM a voice and visibility [9] and who analyze FGM from the perspective of both women and men[10]. Moreover, Ana Silva addressed this problem in her doctoral thesis from the perspective of legal and criminal treatment related to FGM in Spain (Silva Cuesta 2017)[11]. Also, the work of Reig, Siles and 
Solano described the fact that health professionals in Spain have insufficient knowledge about FGM $[12,13]$. Female African leaders created the Inter-African Committee Against Traditional Practices Affecting the Health of Women and Children in 1984, which serves as the basis for global action against FGM. Furthermore, Abusharaf gave a voice to African women in the United States and described the multiple links between the respect and bodily integrity of women, female empowerment, and the economic system [14]. Finally, Hadi analyzes the case of a community of women who had become empowered in the fight against FGM[15]. Gruenbaum describes the socio-cultural dynamics of females genital cutting[16].

We have consulted several studies on the incidence of FGM for sexual health problems: Sharifa \& Abdulrahim analyze the incidence of this practise on women's reproductive health[17] qualifying it as a tragedy for women's reproductive health (Rushwan, 2013)[18]

\section{Methods}

This exploratory-descriptive research, carried out between April 2018 and november 2019, took a qualitative approach and formed part of a research project which had previously analyzed the experiences of women living in Alicante (Spain) who had experienced FGM. These interviews had originally been conducted at the Elche Acoge site (Non-governmental organizations) between September 2018 and November 2019 and included women who had been resident in Spain for at least five years and who spoke Spanish; 18 women who met these requirements. In this current study, we added a complementary criterion that the women we studied develop a level of awareness and sensitivity against FGM (i.e., they were female leaders who campaigned against FGM). We took a critical thinking theoretical focus and followed the principles of Habermas' sociocritical paradigm which states that people who suffer from a given problem have a voice and are more suited to work on its solutionSiles2016[19]. Durkheim et al. $(2004,2006)$ used the concept of 'logic conformism'[20,21], and Bordieu et al. (1999, 2008) used the concept of "habitus" to promote awareness of the process of socially constructing feelings about FGM $[22,23]$. This study used contributions from the social construction of reality and the world as representation related to the practice of $\operatorname{FGM}[24,25]$.

Context and sample: Preliminary Observation and Analysis Unit (AU1) comprised 18 women (W1-18) who had experienced FGM. The secondary observation and analysis unit (AU2) comprised seven women leaders (WL1-7) Who had all lived through transcultural moments and had become activists in the advocate against FGM. To identify relevant cultural moments, we used the categories suggested by Siles [8], employing semi-structured interviews as the data-collection technique and the dialectical structural model of care (DSMC) as the data analysis method[26].

\section{Results And Discussion}

Sociological data: A total of 18 women participated, and their ages ranged from 27 to 61 years (Preliminary Observation and Analysis Unit). Only $38.8 \%$ of the women interviewed were ideologically 
against FGM and were willing to advocate against this practice. About the observation and analysis unit participants.

The secondary observation and analysis unit (B) comprised seven women:

- WL1 was 46 years old, had been born in Guinea Bissau, had been living in Spain for 14 years, was separated, and had a son. She actively participated in an association campaigning against FGM.

- WL2 was a native of Kenya who had been living in Spain for 22 years, was separated, and had three children (two boys and one girl). She actively participated in an association against campaigning FGM.

- WL3: was the youngest at 27 years old, born in Guinea Bissau, had been living in Spain for 15 years, was single, and had no children. She actively participated in an association campaigning against FGM.

- WL4: was 38 years old, had been born in Mali, was married, had three children (one girl and two boys), and had been living in Spain for 12 years. She participated in several associations campaigning against FGM but was not collaborating with any particular one. She found it most difficult to fight against FGM actively and attributed this to the care of her children and husband.

- WL5: was 61 years old, born in Gambia (capital). She is at presently divorced and lives in Spain since 1974(45 years). She had five children (three girls and two boys). WL5

- participated in several associations campaigning against FGM. Also, she became president of a NonGovernmental Organization (NGO).

- WL6: was 49 years old, born in Mali. She is divorced and lives in Spain since 2001. She had two children (two girls). WL6 participated in an association campaigning against FGM.

- WL7: was 38 years old, had been born in Guinea Bissau. She divorced several years ago. WL7 had three children (two boys and a girl). She lives in Spain since 2002. She participated in several associations campaigning against FGM but was not collaborating with any particular one.

\section{Female genital mutilation and health problems}

Women who have experienced 'the rite' (of FGM) and who had become leaders in the advocate against FGM experience a complex and difficult process. In general, knowledge of FGM alone is not a valid or acceptable way to become a 'normal' woman who can be accepted and respected by her community; women must first have access to other cultures and communities in which the role of women is very different to their own experiences. When these women contact strangers from other cultures, they can access different values, beliefs, and norms without having to leave their community of origin.

Nonetheless, the process of acculturation usually occurs through the growing phenomenon of emigration to other countries. Indeed, three of the seven women we interviewed in this present study had become acculturated through experiences and contact with women from other cultures. The health problems that arise from FGM are not considered as such. 
a)Women interpreted difficulties with urination, urinary tract infections, sexual pain, and problems related to penetration as part of normality. They understood that these problems were not the usual ones when they interacted with women from other cultures.

-4 women say they have no desire for sex because of the pain caused during relationships (W1, W3, W5, W7).

-5 women report that they feel a lot of pain in their sexual relationships (W1, W3, W5, W6, W7) but that they thought the pain was normal.

-All women had problems with arousal, lubrication, orgasm and satisfaction.

1. b) Women said they had menstrual problems (dysmenorrhea) and genital infection problems -6 women claim to have menstrual problems (dysmenorrhea, dysregulation) (W1, W2, W3, W5, W6, W7). -6 women had genital infection problems (W1, W2, W3, W5, W6, W7).

1. c) Some of the interviewed women had problems during pregnancy and/or delivery (W3 has no sons).

-4 women had problems in pregnancy (W1, W4, W5, W6).

-3 women had problems in delivery (W3, W5, W6).

1. d) About the psychological problems associated with the GFM.

-All women had psychological problems (anxiety, stress, fear)

\section{Female genital mutilation and cultural moments}

Author A and other (2009) described the influence of multicultural, intercultural, and transcultural factors in the creation of moments which define how women perceive and interpret the ideology FGM and which may alter their level of acculturation or social and communicative integration.

Multicultural moment: the change of place without leaving the cultural isolation Women living in this cultural moment experience that there is a barrier between their way of life, their expectations and their culture. The characteristics of the multicultural moment are in effect, according to two situations:

a)Women are still in Spain for a short time, and they have not yet left their original circle of reference; b)Women, although they carry much time in Spain, are still limited by the influence of their original circle.

In this phase, acculturation that questions the practice of FGM is almost impossible because these women's beliefs and identity linked to the factors above. Nor can they socialize within the context of 
democratic values which project female identity from the perspective of gender equality because these frameworks identify the beliefs that sustain the practice of FGM as unjust, violent, and criminal. The women we interviewed described how, until they had left their country of origin, it had been impossible to take any other view on this socially rooted practice (Figure 1). For instance, WL1 stated, In Guinea, we were all convinced that to be a woman...an honest and respected woman, the tradition was necessary. [...] no one would not have agreed with the rite, although that is not talked about either. [...] lt was just something that did because it had to do. WL2 said, "In Somalia, in the border area between Ethiopia and Kenya, there was no dissidence regarding any tradition, and it was barely to spoken. Everyone knew that you had to do it to girls, yes, but nothing more." WL3 stated, "In Guinea Bissau, among the Fulbes nothing was questioned, and everyone agreed." WL4 said, "In Gambia, there was no cultural pressure to perform the rite. It was something [that was] socially accepted."

WL7 said: "In Guinea Bissau, there is no problem with Female Genital Mutilation because nobody calls tradition as such. All mothers and grandmothers want their daughters and granddaughters respected in the community."

\section{Intercultural moment: the beginning of communication between different cultures}

In this phase, the activation of greater communication and social interaction between different cultures leads women to take a step forward. This situation represents the beginning of a process of recognition and conciliation. Now the new ideas about the role of women in different cultures, which in turn results in an identity transformation. As WL1 put it: A teacher explained girls' female anatomy [to us] and what it was for, especially the female genitalia. This experience was at age 12 in 5 th grade. Although it was difficult, I asked the teacher. All the students looked at me (the teacher had studied in Russia).

It was during the beginning of my stay in Cuba that I began to have doubts because women behave differently. [...] Then, my trip to Cuba supposed a change in my perspective on these things. In general, my stay in Cuba broadened my mind, but everything was still very difficult. In this context, WL2 said, "I had a very bad time. I was hardly a girl anymore; I'll never forget it. I had the infibulation and I had a moment [when I was] tied by the legs, practically without moving for a long time". WL3 described this phase thus: "I began to realize that everything we had been told about female genital mutilation was not entirely true when I started travelling to Spain and I was able to talk with other girls." Similarly, according to WL4, "I started to question things related to female genital mutilation several years after my arrival in Spain because I arrived in 1984, and I began to reflect in 1997."

WL6 said: "When other women told me that the tradition was bad and dangerous to my health, it was difficult for me to understand. When it was understood, I decided that I had to protect my daughter (my husband was preparing the trip to make them the tradition). Finally, I got a divorce... I suffered a lot during the whole process".

During intercultural phases, women start to ask themselves, for the first time, questions about the normality of the symptoms caused by their FGM, but they do not do anything to resolve these problems 
because they are immersed in uncertainty and insecurity (Figure 2).

\section{Transcultural moment: Change of place becomes cultural change}

Cultural socialization occurs as an effect of social interaction and communication between immigrant and native communities, and this causes women to start questioning old beliefs. Migrant women become integrated into associations and receive support from professionals and institutions that facilitate these changes of identity within the framework of democratic societies. Critical thinking is one of the pillars of this transformation and involves a change not only of theoretical approaches and beliefs but also of practices. In line with the sociocritical paradigm[27] \& Solano 2009), some of these women end up actively working in the campaign against FGM and the beliefs that underlie it. In the case of WL1, this transcultural moment occurred when she became sufficiently confident to talk about the tradition of FGM with Cuban women, allowing her to interchange and contrast differences in meanings (Figure 3): In Cuba, [my] friends told me that they had taken something very important from me to feel like a woman and to be able to enjoy my body [...] but what made me change the most was the fact that on my return to Guinea my little sister was being prepared for the rite of initiation. I felt angry and talked with my family, but nobody paid attention to me, and they said that I had gone crazy.

WL2 said, "When I had my daughter, it was very hard, but I was not willing to have it done to her. It was the beginning because I started talking to people about it and that caused me many problems."

WL3 stated the following: We were on holiday in the Pyrenees in July 2005. We were camping with my Spanish father, and there I caught an infection in the genital area. He took me to a medical centre and a gynaecologist or doctor; I do not remember, did an exploration. Afterwards, he called a co-worker (something was out of the ordinary). Later they spoke with my father, who until that day, did not know that female genital mutilation (clitoridectomy) had been practised on me, and it was that day that I discovered that what in my culture was special and was celebrated with gifts, was the opposite, and then I started to live it [my reality] differently.

WL4 recalled, "I contacted people who made me question the ritual in 1997 (I had arrived in Spain in 1984). I am going to write an autobiographical book in which I will talk about all this, and it will help me to reflect [upon it]."

In this transcultural phase, these seven women had been considered traitors by their community and family because they had reacted against FGM. However, they overcame their uncertainty and, in parallel with the fight against FGM, identified their health problems and were able to link them to this practice.

\section{Female genital mutilation from the perspective of the dialectical structural model of care}

Functional unit: The feelings, beliefs, values, traditions and norms (FU) that favour the practice of FGM [26] are not exclusively religious. As WL1 stated: My father is Muslim, but my mother is Catholic, so there was mixing, and the practice transcended the purely religious issue [...] There are many ethnicities and each one has an [different] influence and also looks for different names to insult women who do not want 
tradition. Rather, a series of transversal values (not exclusively religious ones) support this practice, as also described by WL1: "Tradition ensures the purity of women, hygiene, and even femininity; a woman without tradition is not a total woman." Similarly, WL2 said, "Religion influences the rite, but this tradition does not come from the Koran. It is a tradition that must be done, and That,s is that [...] The Masahi are Christians and they also have this tradition [...]." WL3 put it this way:

For the Fulbe culture, my community, it is unthinkable not to do this practice. Female genital mutilation is not exclusive of Islam [or] established in the Koran but is a tradition so ingrained that it is unacceptable not to continue doing it.

WL4 described the following: The community shares the belief that female genital mutilation must be carried out. There is no resistance because the people around [there] do not think about eradicating it. There is no pressure because there is no capacity to decide; there is no need for pressure. This situation is as much for family education as [it is] for street [education].

Functional framework. The functional framework (FF) is constituted by scenarios where the MGF occurs [26]. The tradition of FGM is often carried out in places which are especially prepared and separated from the community, usually in a hut away from the others or even outdoors. It is also sometimes performed in the field near some type of symbol such as a sacred tree (as in the cases of WL1 and WL2, W5). However, in some cases, FGM is practised in the family home, usually in the kitchen (as for WL3). There is also an intermediate place (separated from the community but not where the practice is carried out) where the process of socialization takes place after the mutilation. As affirmed by WL1, "It can last several days, and in its course, the girls indoctrinated about the role of women that they should perform in the future." WL4 decided not to talk about where or how FGM practised on her. The seven women all spoke with great affection for their mothers and grandmothers, but they had all had confrontations with them. These intergenerational confrontations had lasted for a long time, but eventually, they had all spoken with these relatives and had forgiven them.

Functional element: The functional element $(\mathrm{FE})$ is constituted by the people who practice the FGM and also those who are victims of this practice [26]. Older women in these societies, sometimes called 'slicers', or in many cases family grandmothers, usually carry out the tradition of FGM; the community highly respects both. As WL1 confirmed, "Because deep down, the grandmothers are the ones that are going to get the girls to integrate into the community, and they want both the girls and their mothers." WL2 described her FGM thus, "At five years old at my grandmother's house. A cutter was the one that did the practice". For WL3 it was at "Almost five years old. Older women were the ones who [did] the female genital mutilation in a field". WL4 said, "I think it was an old cutter dedicated to these things". More recently the tradition has started to become medically institutionalized, with doctors and nurses starting to perform the practice; according to WL1, "Now doctors also perform the tradition for health reasons, because many girls have died".

\section{Discussion}


Several authors have worked on the relationship between the social construction of gender and the representation of the body: in the process, Laqueur and Scott reviewed the history of the social construction of gender and the incidence of the body[28, 29]. Martínez Barreiro focused on contemporary societies in which bodies are merchandise but into which ancestral practices foreign to the West have imported because of globalization[30, 31 Siles]. Moreover, Alemany-Anchel and Velasco-Laiseca highlighted the cultural tendency to exert greater symbolic violence upon the bodies of women than those of men[32]. Similarly, Foucault studied the incidence of politics in the forms of power exerted on bodies rather than on people's ideologies or consciences[33], and in this same line, Abusharaf y Hadi related to respect for the physical integrity of the female body with the empowerment of women and the economic system[14, 15].

We do not know if FGM was a cause or a consequence of the values, beliefs, or norms for the seven women interviewed in this study. However, they do not doubt that the technology that marks their bodies and reinforces their adhesion to these factors. This body marks also highlight their identity within the category of being female [21]. Scott analyzed the 'gender' category within historical contexts, emphasizing its dynamic character and its four elements: symbols, norms, institutions or social structures, and work[29]; FGM affects all these planes. Likewise, studies by various authors have endorsed changes in these ways of thinking and of acting concerning tradition, after immigrants who have been under the influence of other cultures for a long time undergo the processes of acculturation and Cultural change after migration $[30,31]$

Furthermore, [author(s) 2016] described and analyzed the incidence of FGM in the construction of feminine identity, within the framework of dependency on masculine power[26]. Similarly, several authors have integrated FGM into the process of the social construction of the body[32], supporting the central thesis of Bordieu's habitus[22,23] about symbolic power and male domination. This habitus uses the social construction of the body as a tool for forming structures related to female identity, and socialized subjectivity (interpersonal and intrapersonal interactions) play a determining role in developing this construction. Male power has been creating norms, values, and symbols that nourish argumentation for the cultural construction of gender, enhancing an ideal and exemplary female identity $[12,13]$. Before this masculine power can act on the ideology or conscience of Foucault, a physical technology of the body, such as FGM, must already exist[33].

This situation contributes to the subsequent subjective and intersubjective assimilation of a corollary of beliefs, norms, and values that also extol FGM as an essential bulwark from which the ideal model of women is built [13]. During this process spaces which respect the feminine canon are organized, including the place that women occupy in the home, ceremonies, families, and even verbal and non-verbal ways of expressing themselves and of moving. However, Hadi first described the case of a community of women who had become empowered to advocate against FGM[15].

The results of this study confirm the findings of Sharifa and Abdulrahim: Women have health problems associated with FGM[17]; problems with sexual desire and arousal, pain with penetration and lubrication. 
This study also confirms the existence of problems in women's reproductive health [18, 37]. In addition to describing the process by which women with FGM become leaders; another contribution of this research is to describe the link between women's transcultural experiences (sensitized against the practice of FGM) and the awareness (visibility) of these women about their health problems (urological, sexual, reproductive and psychological).

\section{Conclusions}

The change of location can lead to a decrease in cultural pressure (the cultural pressure that facilitated FGM).

The change to a new country encourages critical thinking and cross-cultural perspectives on the practice of FGM.

The practice of FGM constitutes a significant segment of gender violence. This process of gender violence leads to both physiological and psychological health problems. Factors such as religion and hygiene or the degree of women's purity affect the practice of FGM, but the mechanisms of cultural pressure established for the continuation of this practice (cultural determinants) perpetuate it. The process of acculturation that occurs when women confront other cultures is the essential basis for them to discuss FGM. Acculturation also influences the development of critical thinking and promotes crosscultural moments.

Intergenerational differences between women who have or have not experienced FGM only appear accompanied by transcultural moments. Women after acculturation - a cross-cultural moment - may even become activists and campaigners in fighting FGM (as in the case of the seven women we interviewed in this study).

Health problems associated with female genital mutilation (sexual, reproductive and psychological) become visible at transcultural moments. Therefore, we argue that critical thinking among these women is only possible in situations of transculturality and glocalization.

\section{List Of Abbreviations}

(DSMC)Dialectical Structural Model of Care.

(FGM) Female Genital Mutilation.

(W)Women.

(WL) Women Leaders.

\section{Declarations}




\section{Ethics approval and informed consent}

The Ethics Committee of the University of Alicante (Spain) approved this project on January 2018/Number: UA-2017-12-15.This study is conformed to the ethical principles set out in the Declaration of Helsinki. All the participating individuals signed their informed consent to participation, after having been explained their rights as citizens, the characteristics and objectives of the study, and their guaranteed anonymity.

\section{Availability of data and materials}

The datasets during and/or analysed during the current study available from the corresponding author on reasonable request.

\section{Competing interests}

The authors declare that they have no competing interests.

\section{Funding}

The authors disclosed receipt of the following financial support for the research, authorship, and/or publication of this article: - AICO 2017/18 (Direcció general d'universitat, investigació i ciència. Generalitat Valenciana). This study is part of the "Social Challenges Europe 2020 strategy" program, which considers the current political priorities in the field of European strategy, constituting a priority line: health, demographic change and well-being, integrating a gender analysis which is inherent in the subject treated: Female Genital Mutilation.

\section{Authors' contribution}

JS performed the thematic study, wrote the first draft of the manuscript and developed the methodology as part of a research project. JS also supervised the project and supervised its delivery. CSR and AIGG conducted the interviews, supervised the analysis and the research Project. JS, CSR and AIGG guaranteed the anonymity of sources, responses and ensured that any information was anonymous. All the authors read and approved the final manuscript.

\section{Acknowledgements}

We want to thank the collaboration of all the participants in the research and, also, we express our gratitude to the research group of the University of Alicante in which we are integrated: Culture of Care

\section{Authors' information}

JS is a registered nurse, with a bachelor's degree in pedagogy and a doctorate in cultural history. $\mathrm{He}$ is a professor at the University of Alicante, directs the scientific journal Cultura de los cuidados (https://culturacuidados.ua.es/) and was director of the doctoral program Nursing and Culture of Care. 
JS develops his lines of research in: health anthropology, cultural history and critical thinking and coordinates the nursing and care culture research group. He has directed 38 doctoral theses and published numerous books and articles in high impact international journals. (Google Scholar: https://scholar.google.es/citations? user=igWVXtsAAAAJ\&hl=en/// Research Gate: https://www.researchgate.net/profile/Jose_Siles///Orcid: https://orcid.org/0000-0003-3046-639X

AIGG and CSR are nurses and teachers at the University of Alicante and are integrated in the cultural care research group. They have published several books and articles in international journals. AIGG: RUA; CSR: Orcid: https://orcid.org/0000-0002-1141-0617///Google Scholar: https://scholar.google.es/citations? user=H5g6nr8AAAAJ\&hl=es///Research Gate: https://www.researchgate.net/profile/Mcarmen_SolanoRuiz

\section{Data sharing}

The datasets used and/or analysed during the current study are available from the corresponding author on reasonable request.

\section{References}

1. Grassivaro P, and Busatt S. Double FGM in Uganda: A case study. International Journal of Anthropology. 2009; 24: 131-46.

2. Kerubo KR. Female genital mutilation- effects on women and young girls. Thesis. Programme Social Services Diaconia: University of Applied Sciences; 2010.

3. Ali AA. Knowledge and attitudes of female genital mutilation among midwives in Eastern Sudan. Reproductive Health. 2012; 9: 23.

4. Asresash D, Abathun JS, and Abdi AG. Attitude toward female genital mutilation among Somali and Harari people, Eastern Ethiopia. International Journal of Women's Health. 2016; 8: 8557-569. doi: https://doi.org/10.2147/IJWH.S112226

5. Berg RC, and Denison E. Interventions to reduce the prevalence of female genital mutilation/cutting in African countries. Campbell systematic reviews. 2012; 9: 24-29. Retrieved of https://campbellcollaboration.org/library/interventions-to-reduce-prevalence-female-genitalmutilation-in-africa

6. Isman E, Vanja B, and Carl E. Perceptions and experiences of female genital mutilation after immigration to Sweden: An explorative study. Social \& Reproductive Healthcare. 2013; 4: 93-98. doi: 10.1016/j.srhc.2013.04.004.

7. Behrendt A, and Moritz S.Posttraumatic Stress Disorder and Memory Problems After Female Genital Mutilation Female Genital Mutilation. The American Journal of Psychiatry. 2005; 162(5): 10001002.

8. Siles $\mathrm{J}$, et al. Una mirada a la situación científica de dos especialidades esenciales de la enfermería contemporánea: la antropología de los cuidados y la enfermería transcultural. Cultura de los 
Cuidados. 2001; 10: 64-72

9. Pastor $M^{a}$. La voz de las mujeres sometidas a mutilación genital femenina: saberes para la disciplina enfermera.; 2014. Retrieved from http://www.tdx.cat/handle/10803/284894

10. Jiménez-Ruíz I. Enfermería y Cultura: las fronteras del androcentrismo en la Ablación/Mutilación Genital Femenina. Murcia: Universidad de Murcia; 2015.

11. Silva Cuesta A. La mutilación genital femenina:aspectos jurídico-penales. Granada: Universidad de Granada; 2017.

12. Reig M, Siles J, and Solano C. Attitudes towards female genital mutilation: an integrative review. International Nursing Review. 2014; 61: 25-34

13. Reig M, Siles J, and Solano C. A mixed-method synthesis of knowledge, experiences and attitudes of health professionals to Female Genital Mutilation. Journal of Advanced Nursing; 2016; 72: 245-260.

14. Abusharaf RM. Female Circumcision: Multicultural Perspectives. Philadelphia: University of Pennsylvania Press; 2017.

15. Hadi S. A Community of Women Empowered: The Story of Deir El Barsha. In. Female circumcision: multicultural perspectives. Edited by Abusharaf RM 104-124. Philadelphia: University of Pensylvania press; 2017.

16. Gruenbaum E. Socio-cultural dynamics of female genital cutting: Research findings, gaps and directions. Culture Health \& Sexuality. 2005; 7(5): 429-41.

17. Sharifa AA, \& Abdulrahim AR. Sexual function in women with female genital mutilation Fertility and Sterility. 2010; 93: 721-724. doi:10.1016/j.fertnstert.2008.10.035.

18. Rushwan H. Female genital mutilation: A tragedy for women's reproductive African Journal of Urology. 2013; 19: 130-133

19. Siles J. La utilidad práctica de la Epistemología en la clarificación de la pertinencia teórica y metodológica en la disciplina enfermera. Index Enferm. 2016; 25(1-2): 86-92.

20. Durkheim E. Las Reglas del Método Sociológico. México DF: Colofón; 2014.

21. Durkheim, E Estructura social y subjetividad. Hidalgo: Ediciones Universidad Autónoma del Estado de Hidalgo; 2016.

22. Bourdieu, P, Wacquant, L. Una invitación a la sociología reflexiva. Buenos Aires: Siglo Veintiuno; 2008.

23. Bourdieu, P. Sobre el poder simbólico. Intelectuales, política y poder. Buenos Aires: EUDEBA; 1999.

24. Berger PL, Luckman T. La construcción social de la realidad. Buenos Aires: Amorrortu;2017

25. Chartier R. El mundo como representación: Historia cultural. Entre las prácticas y la representación. Barcelona: Gedisa; 2009.

26. Siles J. and Solano C. El modelo estructural dialéctico de los cuidados. Una guía facilitadora de la organización, análisis y explicación de los datos en investigación cualitativa. Investigação Qualitativa em Saúde.2016; 2(3): 211-220. 
27. Siles J, and Solano C. Antropología educative de los cuidados. Una etnografía del aula y las practicas clínicas. Alicante: Instituto Ciencias de la Educación-Universidad de Alicante. 2009.

28. Laqueur, T. (1994) La construcción del sexo. Cuerpo y género desde los griegos hasta Freud. Madrid: Cátedra.

29. Scott JW. Gender: a Useful Category of Historical Analysis. American Historical Review. 1986; 91:1053-1075.

30. Martínez-Barreiro, A (2004) La construcción social del cuerpo en las sociedades contemporáneas. Barcelona: Universitat Autónoma de Barcelona.

31. Siles J.La naturaleza histórica y dialéctica de los procesos de Globalización- Glocalización y su incidencia en la cultura de los cuidados. Index de Enfermería, 19(2-3): 162- 166.

32. Alemany-Anchel MJ, and Velasco-Laiseca J. Género, imagen y representación del cuerpo. Index de Enfermería. 2008; 17(1): 39-43.

33. Foucault, M. Tecnologías del yo y otros textos afines. Barcelona: Paidos; 2008.

34. Gele AA, Johansen EB, and Sundby, J.When female circumcision comes to the West: Attitudes toward the practice among Somali Immigrants in Oslo. BMC Public Health. 2012; 27,12:697. doi: 10.1186/1471-2458-12-697.

35. Johnsdotter S, Birgitta Essén Cultural change after migration: Circumcision of girls in Western migrant communities. Best Practice \& Research Clinical Obstetrics and Gynaecology. 2016; 32, $15 \mathrm{e} 25$

36. Kiragu K. Female genital mutilation: a reproductive health concern. Popul Rep J. 1995; 41: 1-4.

\section{Figures}
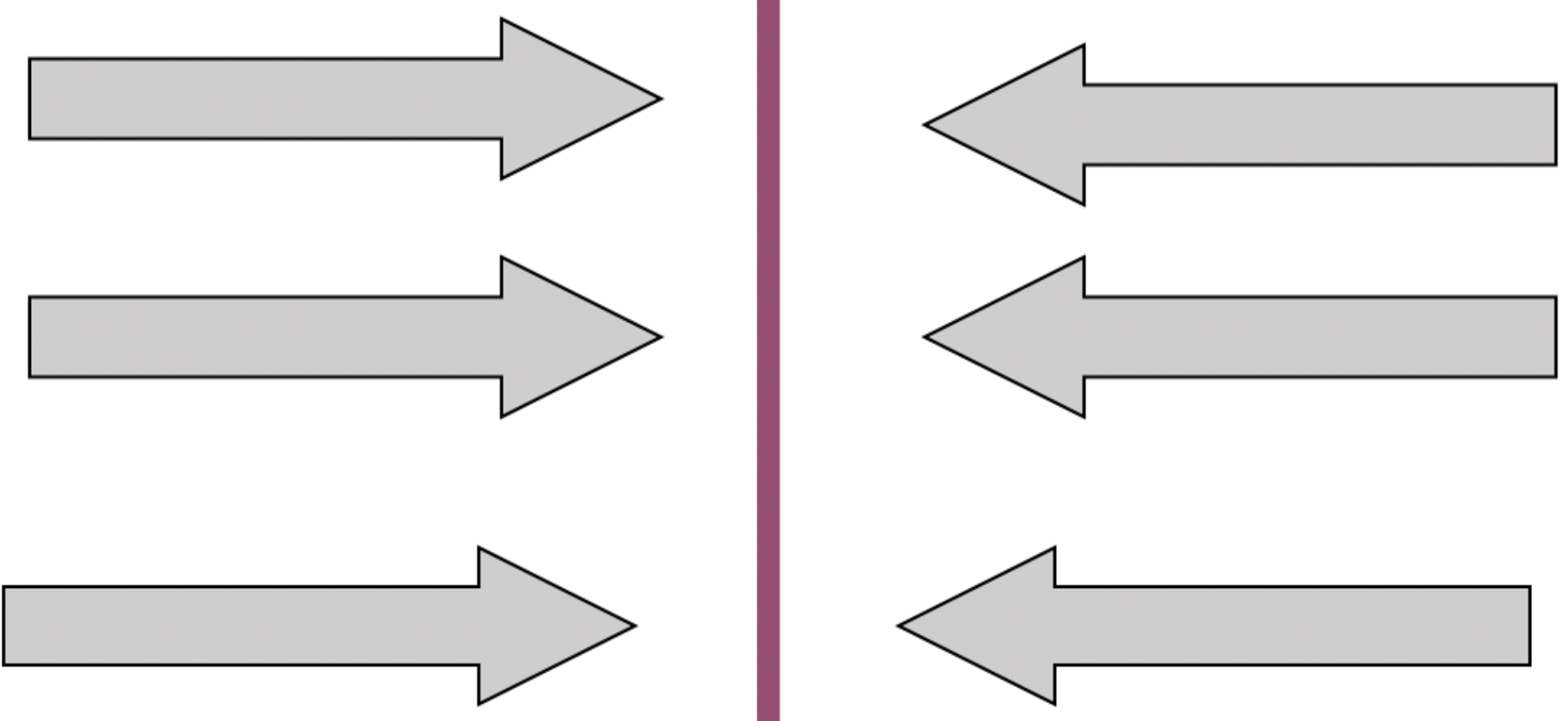
Figure 1

Cultural Moments: FGM and Multiculturalism
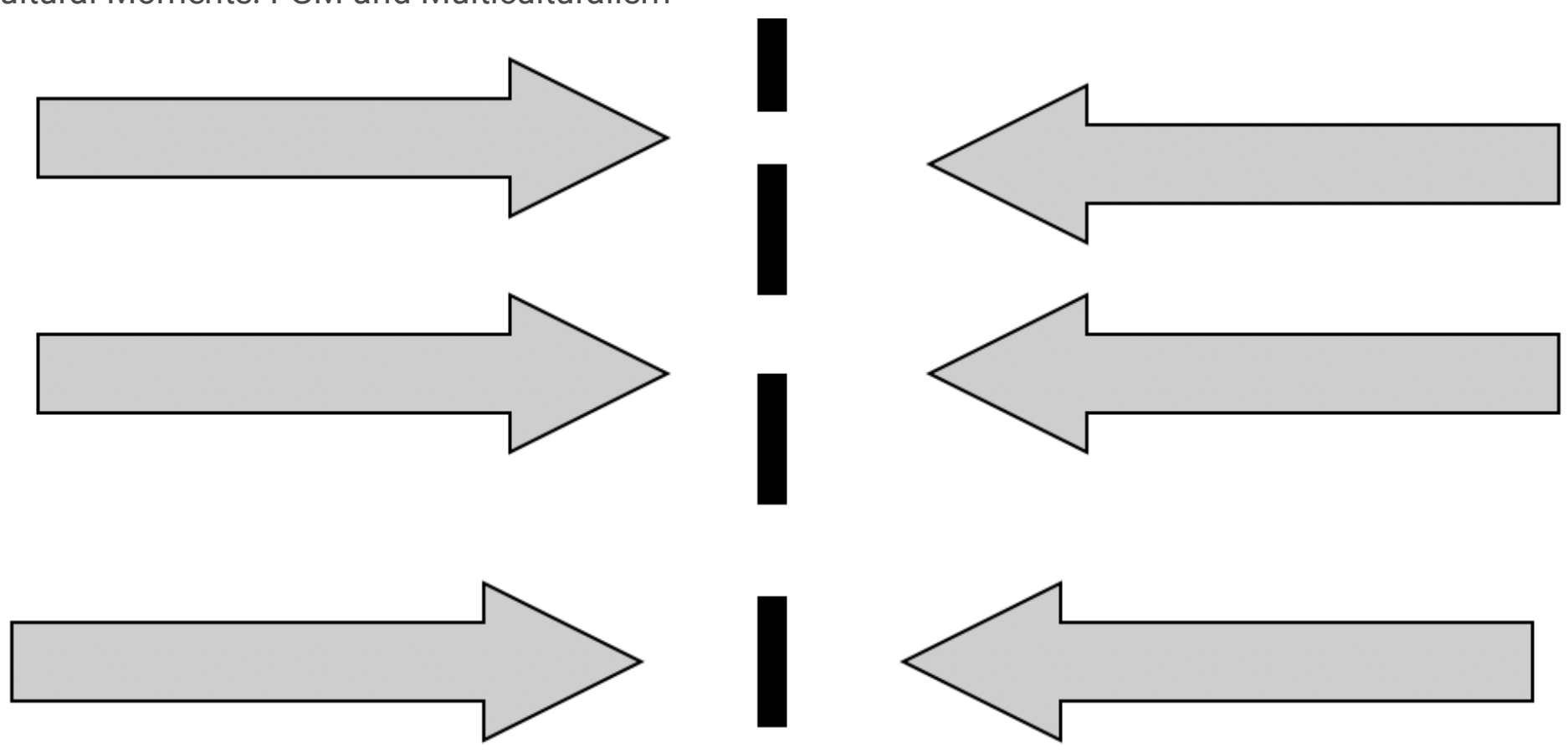

Figure 2

Cultural Moments: FGM and Interculturalism 


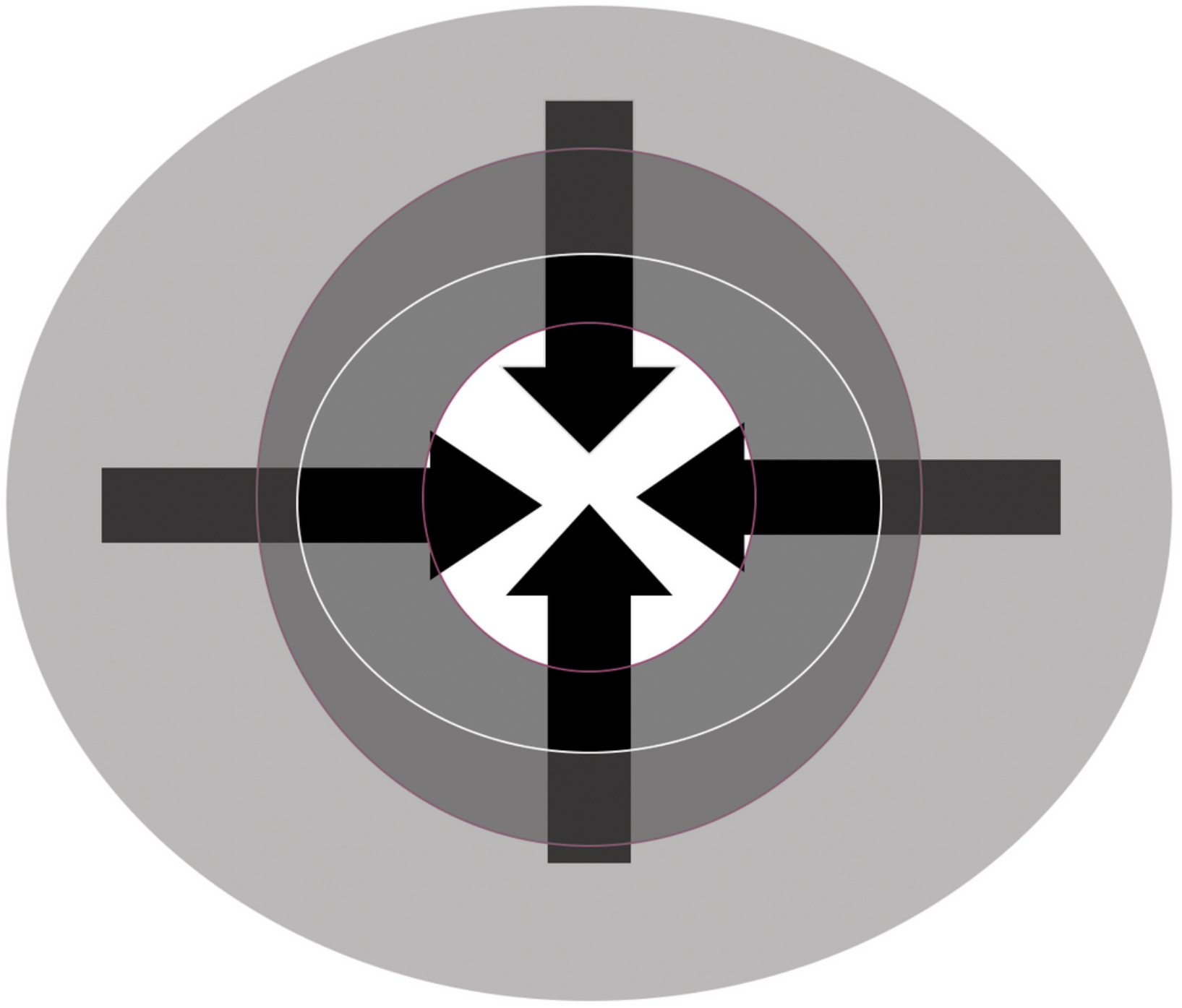

Figure 3

Cultural Moments: FGM and Transculturalism 